\title{
ANNOTATIONS
}

\section{Congenital Syphilis}

The treatment of congenital syphilis is of great importance to ophthalmic surgeons inasmuch as some of the most serious and crippling manifestations of that disease concern the eye. A recent discussion held by the Medico-Chirurgical Society of Edinburgh, and reported in the Edinburgh Medical Journal brought out several important points in the causation, diagnosis and treatment (Edin. Med. Jl., May, 1924). Not that any agreement was reached on the latter point, as, indeed, was hardly to be expected, but the various views brought forward were well debated. The discussion was opened by Mr. David Lees. He expressed a preference for sulpharsenol for intramuscular but not for intravenous use and laid great stress on the necessity for beginning treatment within a few hours of birth. $\mathrm{He}$ also dealt with alternative methods of treatment at considerable length. Dr. Leonard Findlay, who followed him, agreed with his main points and expressed the opinion that the prevalence of congenital syphilis, in Glasgow at any rate, had been considerably exaggerated. He considered that arsenical treatment in interstitial keratitis was of little value, an opinion with which some of the other contributors to this most interesting debate did not agree. The discussion is well worth reading.

\section{The Medical Treatment of Cataract}

The letter which we publish in this issue from Mr. George Young of Colchester, is timely and of great importance. At the present time the cry of "cataract cured without operation" is much to the fore, and whether the means used consist of drops or ointments inserted into the conjunctival sac or solutions injected under the conjunctiva it behoves ophthalmologists to proceed with caution. We do not for a moment suppose that anyone of standing in the profession, save, of course, the therapeutic crank, will be led away by this cry. It is notorious that when changes are developing in the lens the vision may vary almost from week to week. We have always held that it is inadvisable to mention the word cataract to any patient whose visual acuity is normal or nearly normal, no matter what the condition of the lens may be, and we feel that there are few patients, in this country at any rate, who will embark upon a cure for anything without first understanding what that something is, that is to be cured.

Our knowledge of the causes and pathology of cataract is not yet sufficient to enable us to say for certain how soon striae, which 